Article

\title{
Surface Porosity of Natural Diamond Crystals after the Catalytic Hydrogenation
}

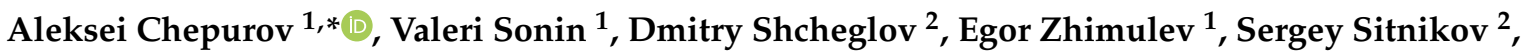 \\ Alexander Yelisseyev ${ }^{1}$ and Anatoly Chepurov ${ }^{1}$ \\ 1 Sobolev Institute of Geology and Mineralogy SB RAS, 630090 Novosibirsk, Russia; sonin@igm.nsc.ru (V.S.); \\ ezhimulev@igm.nsc.ru (E.Z.); eliseev@igm.nsc.ru (A.Y.); chepurov@igm.nsc.ru (A.C.) \\ 2 Rzhanov Institute of Semiconductor Physics SB RAS, 630090 Novosibirsk, Russia; sheglov@isp.nsc.ru (D.S.); \\ sitnikov@isp.nsc.ru (S.S.) \\ * Correspondence: achepurov@igm.nsc.ru
}

Citation: Chepurov, A.; Sonin, V.; Shcheglov, D.; Zhimulev, E.; Sitnikov, S.; Yelisseyev, A.; Chepurov, A. Surface Porosity of Natural Diamond Crystals after the Catalytic Hydrogenation. Crystals 2021, 11, 1341. https://doi.org/10.3390/ cryst11111341

Academic Editor: Volodymyr Bon

Received: 12 October 2021

Accepted: 30 October 2021

Published: 3 November 2021

Publisher's Note: MDPI stays neutral with regard to jurisdictional claims in published maps and institutional affiliations.

Copyright: (c) 2021 by the authors. Licensee MDPI, Basel, Switzerland. This article is an open access article distributed under the terms and conditions of the Creative Commons Attribution (CC BY) license (https:// creativecommons.org/licenses/by/ $4.0 /)$.

\begin{abstract}
The study of diamond surfaces is traditionally undertaken in geology and materials science. As a sample material, two natural diamond crystals of type Ia were selected, and their luminescence and nitrogen state was characterized. In order to etch the surface catalytic hydrogenation was performed using Fe particles as an etchant. Micromorphology of the surface was investigated by scanning electron and laser confocal microscopy. It was demonstrated that etching occurred perpendicular to the crystal surface, with no signs of tangential etching. The average depth of caverns did not exceed 20-25 $\mu \mathrm{m}$ with a maximal depth of $40 \mu \mathrm{m}$. It is concluded that catalytic hydrogenation of natural type Ia diamonds is effective to produce a porous surface that can be used in composites or as a substrate material. Additionally, the comparison of results with porous microsculptures observed on natural impact diamond crystals from the Popigai astrobleme revealed a strong resemblance.
\end{abstract}

Keywords: diamond; etching; surface; impact diamond

\section{Introduction}

The study of diamond surfaces is traditionally undertaken in geology and materials science. The main trends of post-growth changes during transportation by kimberlite melts have been demonstrated [1-5] as well as the conditions of diamond preservation in the deeper mantle [6-8]. In materials science, such studies are mainly aimed at using diamonds as a substrate [9-13] or part of a composite [14,15], and in novel applications such as in the elements of biosensors [16]. The use of diamond as a substrate is mainly limited by the fact that most metals slightly wet the diamond surface, and only by the addition of carbide-forming metals to the alloys can the contact angle be significantly decreased [17]. In most cases, a weak contact between the diamond and metal occurs, and as a consequence, the lack of a strong application of metal particles to the diamond surface limits progress in this field. At the same time, diamond is a very interesting material as a substrate, because it has many unique properties, such as extreme chemical, mechanical, and radiation resistance, as well as high thermal conductivity and optical transparency [18].

In order to produce a certain degree of surface roughness, different etching procedures are used. The most effective are oxygen [19-21] or hydrogen [22] plasma treatment and contact etching by metals in a solid state [23-28]. These treatments produce numerous etching pits, thus forming a cavernous surface on the diamond. Recent experiments demonstrated that even synthetic HPHT (high-pressure high-temperature) diamond single crystals can become a porous substrate through catalytic hydrogenation [26]. A new, interesting example of a porous diamond is HPHT diamond synthesis in metal melt, obtained by varying the growing medium [29]. Our recently obtained results as well demonstrated the growth of HPHT diamonds with numerous caverns which were formed by the presence of solid components in the metal melt [30], as predicted earlier [31]. It 
is worth noting that several kinds of diamond materials are available today: natural crystals extracted from kimberlite deposits, several types of synthetic diamond produced by HPHT and Chemical Vapour Deposition (CVD) technologies, and synthetic detonation diamonds. The majority of experiments are carried out with synthetic diamond varieties, while studies of the etching of natural diamond by modern techniques are less common. However, this remains relevant not only for the industrial application of natural diamond but also for understanding the conditions of formation of rare types of natural diamond. An example is the impact diamond from the Popigai astrobleme (Russia) [32], and its variety "Yakutite" [33]. The surface of impact diamonds most often includes complex microrelief elements while their genesis is not yet clarified. It should be added that the diamond resources at impact locations such as the Popigai deposit are enormous, estimated at 140 billion carats with an average grade of 23.23 carats per ton [34], though their use is very limited now. The present paper reports the results of catalytic hydrogenation of natural diamond crystals and their detailed characterization, aiming to obtain a highly porous surface of natural diamond and to compare the surface micromorphology with that of diamond crystals from the Popigai astrobleme.

\section{Materials and Methods}

As a sample material, we selected two natural flat-shaped diamond crystals of octahedral habit (samples PA-1-19 and PA-2-19). Both diamonds were colorless crystals, about $2 \mathrm{~mm}$ in size. They were free of internal fractures, inclusions, or other visible imperfections. Natural diamond crystals of the Popigai astrobleme were selected from the collection of V.S. Sobolev Institute of geology and mineralogy SB RAS. The transparent crystals were characterized. A detailed study of the physical properties of such diamonds was performed earlier [35,36].

The photoluminescence patterns for the samples were obtained by UV excitation of $365 \mathrm{~nm}$ from a $120 \mathrm{~W}$ mercury lamp. The absorption spectra were recorded using a Fourier-transform Infralum 801 spectrometer. Calibration of the absorption spectra was made by taking the proper absorption in the diamond lattice at the point $2000 \mathrm{~cm}^{-1}$ equal to $12.31 \mathrm{~cm}^{-1}$ [37]. The absorption spectra in the one-phonon region of the spectrum were decomposed into individual $\mathrm{A}$ and $\mathrm{B}$ components. The concentration of impurity nitrogen in the form of A centers (a pair of substitution nitrogen atoms in adjacent positions in the diamond lattice) and $B$ centers (nitrogen vacancy complex $\mathrm{N}_{4} \mathrm{~V}$ ) were estimated using the following formulas:

$$
\mathrm{N}_{\mathrm{A}}(\mathrm{ppm})=17.5 \mu_{1282}\left(\mathrm{~cm}^{-1}\right)
$$

in Reference [38] and

$$
\mathrm{N}_{\mathrm{B}}(\mathrm{ppm})=35 \mu_{1175}\left(\mathrm{~cm}^{-1}\right)
$$

in Reference [39].

Here $\mathrm{N}_{\mathrm{A}}$ and $\mathrm{N}_{\mathrm{B}}$ are nitrogen concentrations in ppm, whereas $\mu_{1282}$ and $\mu_{1175}$ are the absorption coefficients in the characteristic absorption bands. Estimated concentrations of nitrogen in the form of $\mathrm{A}$ and $\mathrm{B}$-centers are the following:

$$
\begin{aligned}
& \text { Diamond PA-1-19: } \mathrm{N}_{\mathrm{A}}=438 \mathrm{ppm}, \mathrm{N}_{\mathrm{B}}=140 \mathrm{ppm} ; \\
& \text { Diamond PA-2-19: } \mathrm{N}_{\mathrm{A}}=613 \mathrm{ppm}, \mathrm{N}_{\mathrm{B}}=280 \mathrm{ppm} .
\end{aligned}
$$

In order to produce a porous surface, catalytic hydrogenation was carried out using a laboratory-made high-temperature water-cooled microfurnace according to the state assignment of the Institute of Geology and Mineralogy SB RAS. Fe particles were used as an etchant, and the procedure is described in our earlier publications [24,40-42]. Hydrogenation is a chemical reaction between molecular hydrogen $\left(\mathrm{H}_{2}\right)$ and another compound (in particular graphite or diamond), usually in the presence of a catalyst such as $\mathrm{Fe}, \mathrm{Co}$, $\mathrm{Ni}, \mathrm{Pt}, \mathrm{Pd}$. The process is commonly employed to reduce or saturate organic compounds (methane and other hydrocarbons). This process generally involves four steps: (1) diamond 
dissolution and incorporation of carbon atoms into the surface layer of the metallic catalyst, (2) carbon diffusion in the bulk of the metal, (3) gasification of the carbon dissolved in the metal via the formation of gaseous hydrocarbons, and (4) the removal of the gaseous carbon-containing compounds from the reaction zone [43-45]. The mechanism of catalytic hydrogenation of diamond is influenced by the diamond structure (crystallographic orientation of the faces on which the etching occurs), as well as the presence of defects in the form of dislocations, and the size of the catalyst particles [46,47]. After etching, the diamond crystals were cleaned in a mixture of $\mathrm{HCl}$ and $\mathrm{HNO}_{3}$ to remove the metal, as well as in an oxidative mixture consisting of $10 \%$ aqueous solution of $\mathrm{K}_{2} \mathrm{Cr}_{2} \mathrm{O}_{7}$ and concentrated $\mathrm{H}_{2} \mathrm{SO}_{4}$ at a ratio of 1:3. This is a conventional procedure to remove graphite and organic compounds, whereas diamond is not oxidized [48].

The diamond surface was examined in CKP "Nanostruktury" (Novosibirsk, Russia) using a scanning electron microscope (LEO 1430 and 1540 XB Crossbeam, Zeiss, Stuttgart, Germany) and laser confocal microscope (LSM 800 MAT, Zeiss, Tokyo, Japan). The confocal microscopy images were obtained using a $405 \mathrm{~nm}$ laser and the pinhole was set to 1 Airy unit. The topology image of the etching area was obtained by stitching $4 \times 4$ tile dataset with 50 z-stacks per tile, the tile grid had a $10 \%$ overlap between neighboring tiles in the XY plane. The topology image of single caverns was obtained from the z-stack confocal image with 150 slices. Surface topology analysis was carried out by using ConfoMap (Zeiss, Jena, Germany).

\section{Results}

In Figure 1 the photoluminescence patterns for the crystals PA-1-19 and PA-2-19 obtained by UV excitation of $365 \mathrm{~nm}$ from a $120 \mathrm{~W}$ mercury lamp are given: these are (a) and (b) sections, respectively. On the right, the optical absorption spectra in the mid-IR range for the corresponding crystals are shown. The spectra demonstrate the characteristic absorption of the diamond lattice in the range $1800-2800 \mathrm{~cm}^{-1}$. In the one-phonon region, intense absorption of nitrogen centers A and B is seen with major maxima of about 1282 and $1175 \mathrm{~cm}^{-1}$, respectively.
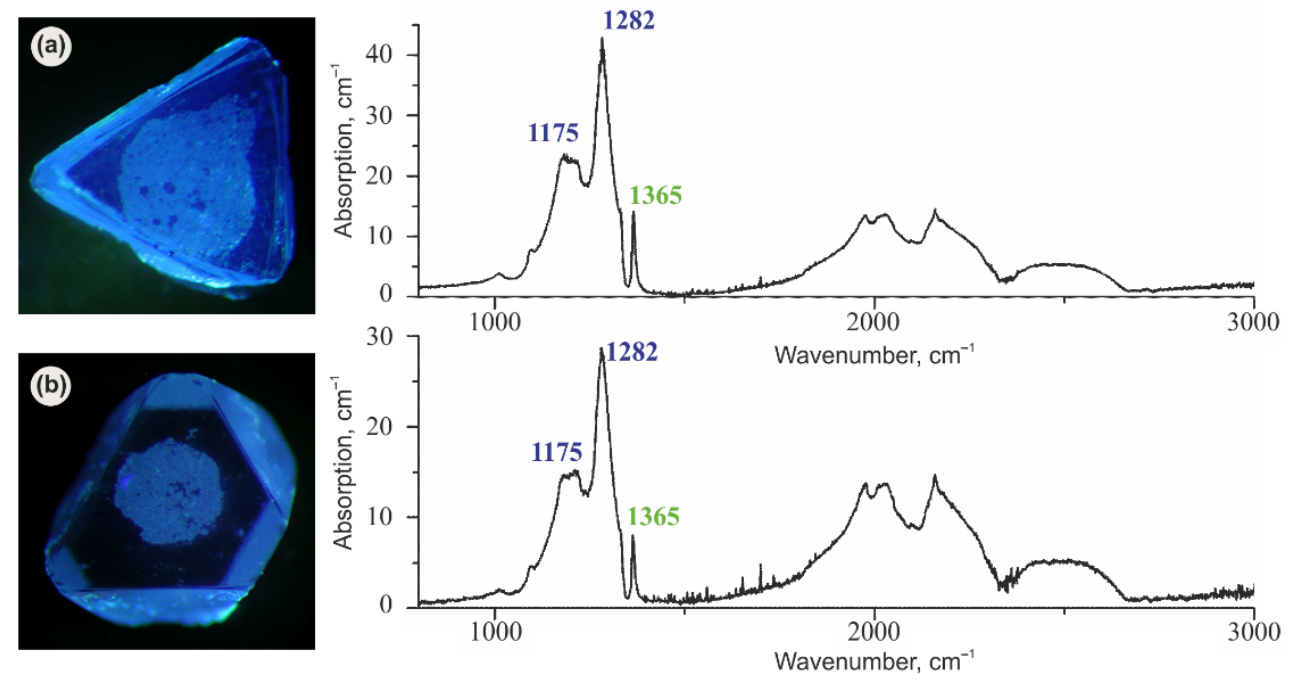

Figure 1. Photoluminescence patterns of the natural diamond crystals PA-1-19 (a) and PA-2-19 (b), obtained at UV $365 \mathrm{~nm}$ excitation. The rounded-shaped spot on the top face is a result of thermochemical etching. IR absorption spectrum for each crystal is given on the right side. Peaks near 1175, 1282, and $1365 \mathrm{~cm}^{-1}$ are associated with B, A nitrogen defects, and B' structural defects (platelets), respectively.

In the absorption spectra shown in Figure 1, there is also a fairly intense line ( 8 to $14 \mathrm{~cm}^{-1}$ ) of about $1365 \mathrm{~cm}^{-1}$ associated with lamellar structural defects (platelets or B' centers) in diamonds. Thus, these crystals are characterized as Ia-type diamonds in frames 
of the physical classification [49]. As seen in Figure 1 diamonds are dominated by blue photoluminescence, uniformly distributed in the volume of the samples. Such a blue luminescence pattern is common for most natural kimberlite diamonds. The luminescence spectrum is dominated by a vibronic N3 system with the zero-phonon line at $415.2 \mathrm{~nm}$. This system is associated with the complicated nitrogen-vacancy complex $\mathrm{N}_{3} \mathrm{~V}$, where $\mathrm{N}$ is nitrogen and $\mathrm{V}$ is vacancy [37]. There are several excellent reviews of diamond spectroscopy [37,50-52], and a very nice color chart [53].

After the etching of the diamond crystals by Fe particles, their surface became roughly cavernous throughout the area where the reagent was applied (Figure 2a). The procedure produced etching of a normal type, perpendicular to the diamond face (Figure $2 b$ ). We found no tangential-type of etching, which is characterized by channels parallel to diamond faces [24,46]. The microrelief consisted of numerous etching pits and caverns of a pseudo-rounded shape; the width of such individual caverns was in most cases about $10 \mu \mathrm{m}$ (Figure $2 \mathrm{~b}, \mathrm{c}$ ). A detailed study of the micromorphology of the caverns confirmed they contained smaller relief elements: the walls of each cavern consisted of numerous etching pits and hillocks thus forming a highly porous surface even within a single cavern (Figure 2c,d).
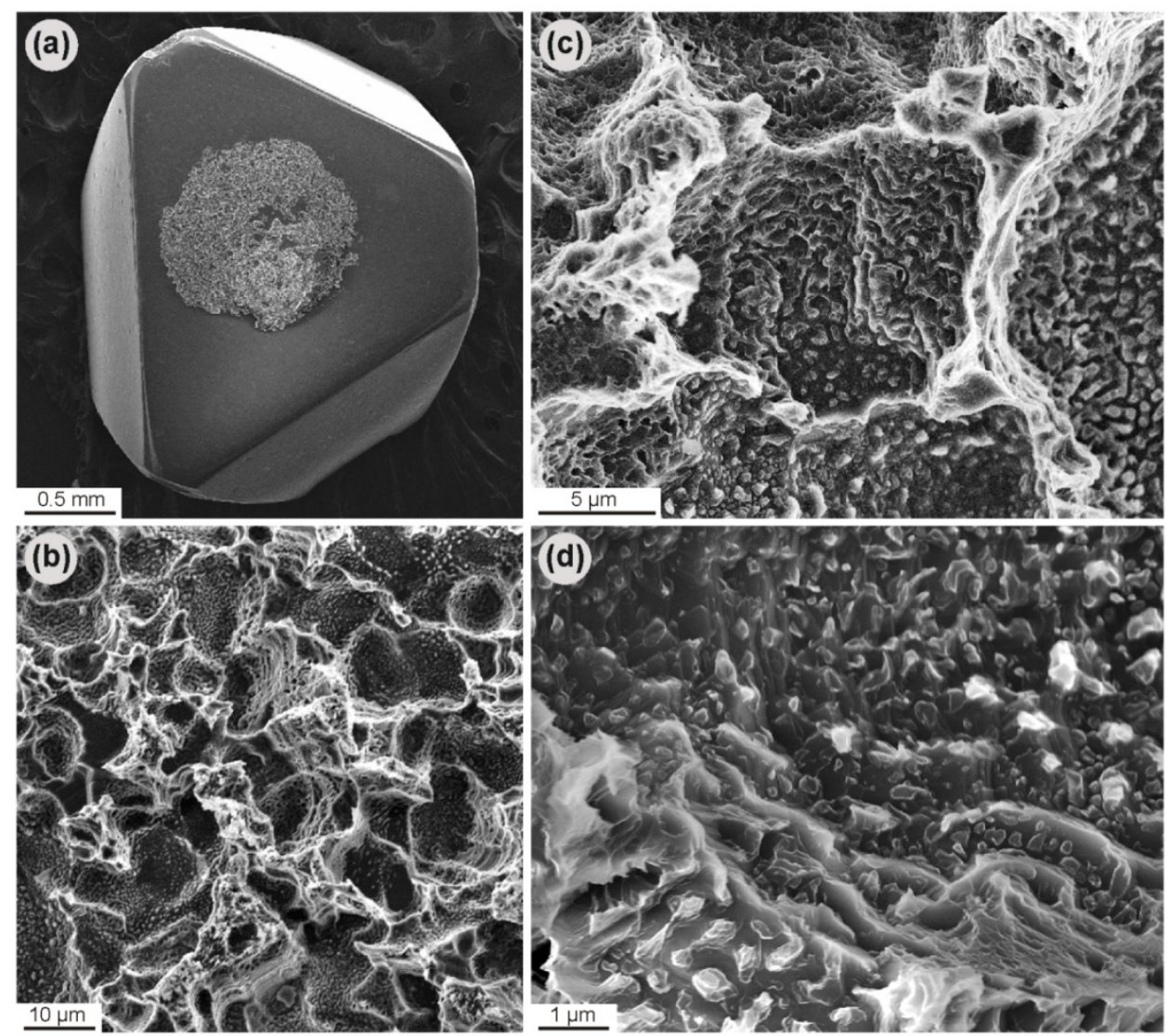

Figure 2. Natural diamond crystal with an etched area on octahedron face (a) and micrographs of the etched surface: (b) - general view of the etching sculptures; (c) —an individual cavern with numerous smaller relief elements, and their detailed view (d).

The average depth of caverns in most cases did not exceed 20-25 $\mu$ m with a maximal depth reaching $40 \mu \mathrm{m}$ (Figure 3a). The caverns have almost vertical walls (Figure 3b). 

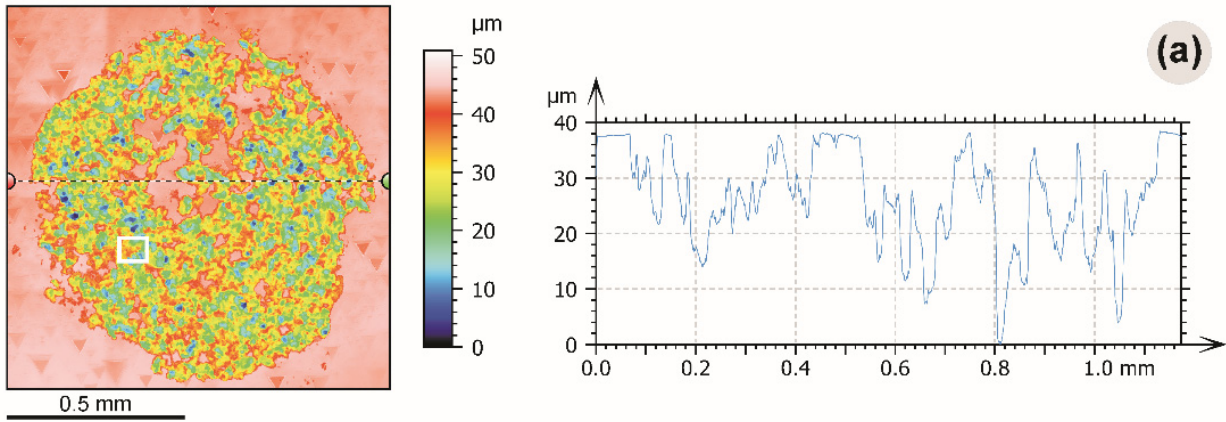

(a)
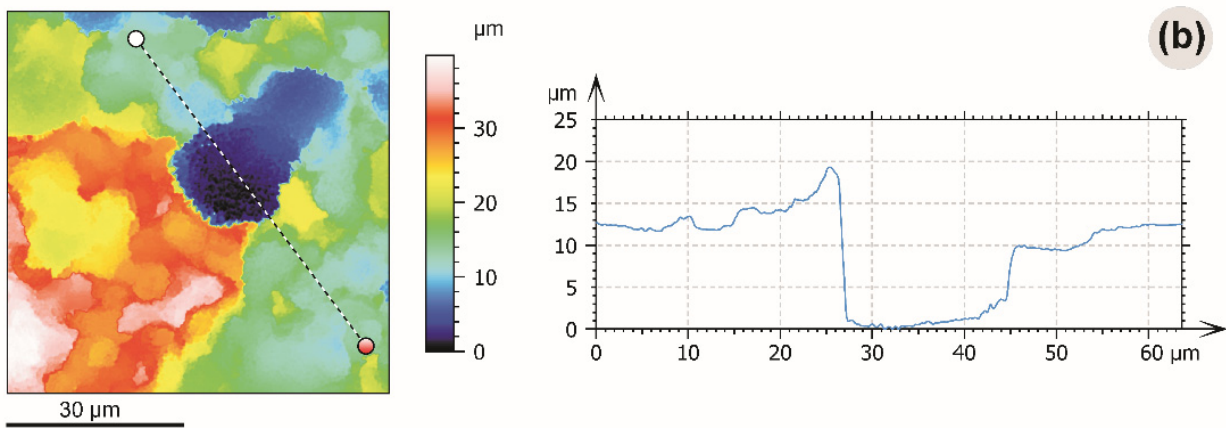

Figure 3. Confocal laser microscopy images demonstrate the surface relief of the diamond crystal shown in Figure 2a: (a) scan through the whole etching area. Dotted lines mark the position of the profile shown at the right side of each picture; the white square on (a) indicates the location of the scanned area presented on (b). Small triangles on (a) are attributed to the evolution of this diamond in nature, but not to our experimental procedure.

The selected natural impact diamonds were typical small grains without facets (Figure 4a). They show a porous surface that covers almost the whole crystal (Figure $4 \mathrm{~b}$ ). The porosity consists of oval or irregular-shaped caverns (Figure 4c).
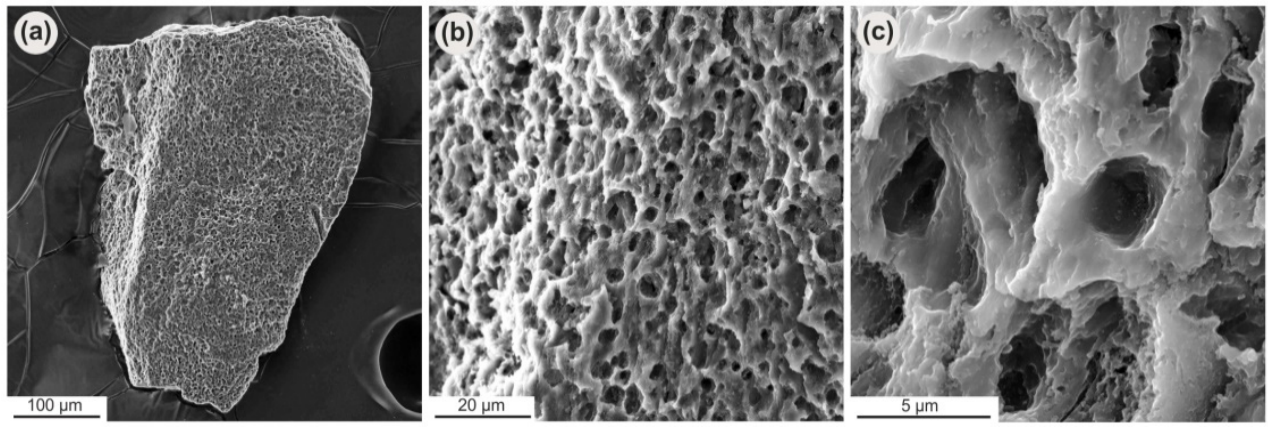

Figure 4. General view of the impact diamond crystal from the Popigai astrobleme (a); the porous surface at higher magnification (b), and the details of the microstructure of the individual caverns (c).

\section{Discussion}

In this study, we aimed to perform etching and characterization of the surface of a natural diamond. In order to treat the crystals, we used hydrogenation by Fe particles. This technique has already demonstrated high etching rates on other diamond types [24,40-42], while the distribution of metal particles on the diamond and the characteristics of the etched surface depend mainly upon the method of preparation of the etchant [47]. Our recent study on synthetic diamond crystals confirmed that the size of the pits can be decreased significantly [26]. In the present experiment, we used a similar procedure, but a natural diamond was the sample material. It is worth noting that the porous surface obtained after the removal of Fe particles in acids consisted completely of diamond. As a result, the etching occurred perpendicular only to the crystal surface, but the caverns obtained were 
larger (Figures 2 and 3). They had a depth of up to $40 \mu \mathrm{m}$ (Figure 3) which means the depth of Fe particles penetration into the diamond. It is important to add that for the present experiment we selected the most common type Ia nitrogen-containing diamonds which make up about $99 \%$ of all natural diamonds mined worldwide [54]. The selected crystals were very similar to each other from a physical point of view, as they contained almost the same total amount of nitrogen, which concentrates mainly in the form of A-centers. Both crystals had typical blue luminescence (Figure 1).

The larger size of the caverns is probably a result of the presence of numerous dislocations in these natural crystals. This is supported by the presence of triangular-shaped etching pits of a natural origin (Figure 3a) and is considered the main reason natural kimberlite diamonds are easily etched by the thermochemical process [40]. In addition, it can be suggested that the etching of common synthetic HPHT diamond forms smaller caverns since it contains fewer dislocations. As a result, its etched surface consists of smaller elements [26]. The mechanism was discussed in detail and compared the etching relief with that of an as-grown HPHT diamond. In the present study, each cavern wall consisted of numerous smaller relief elements (Figure 2), which are probably a result of etching by tiny individual Fe nanoparticles of a submicron size. This submicroscopic relief expanded in all directions within the cavern. Therefore, it can be concluded that porous natural diamond etched by hydrogenation can be used in composites or as a substrate material.

Not much information is available in the literature about surface etching of impact diamond, which is another kind of natural diamond. This variety consists of a combination of cubic and hexagonal carbon and thus contains more structural defects [35,55]. Its surface microrelief also includes specific microsculptures [36] which are a vivid example of porous diamond (Figure 4). The surface of thermochemically etched crystals from the present experiment demonstrated similar relief elements to those found on impact diamond crystals from the Popigai astrobleme; small oval or irregular-shape caverns with numerous smaller relief elements within (Figure 3).

Elemental carbon (graphite or diamond) is a strong reducing agent at a normal pressure (0.1 MPa), capable of reducing Fe from silicate and oxide phases [56]. Such conditions could have existed after the impact event in the heated rocks of the Popigai crater. As a result, iron particles may have appeared on the surface of impact diamond crystals. Spherules of Ni-Fe have been found in the impact tuffisites of the Popigai crater [57], indicating a highly reduced environment. Metallica iron particles were also identified in rocks of the Janisjärvi impact crater in Karelia (Russia). Furthermore, specific linear or fan-like channels up to several microns wide, as well as numerous tube-shaped tunnels [58] and round or irregular etching pits were observed on the surface of impact diamonds from that crater. Similar textures were reported for diamonds from the Ries [59,60] and Popigai [61] impact craters. At high magnification, the channels have a flat bottomed U-shape that is a typical result of migration of metallic particles over the surface during catalytic hydrogenation of diamond. It should be noted that, along with the oxidation process, the C-O-H system equilibrated with diamond (graphite) can experience a Fe- or Ni-catalyzing hydrogenation in the presence of molecular hydrogen. As a result, the micrometer sized iron particles can produce etching channels along the crystal surface [24], as well as tunnels [40,42], as shown in Figure 5.

It is widely accepted that most natural diamonds are etched by $\mathrm{H}_{2} \mathrm{O}$ or $\mathrm{CO}_{2}$ fluids, and the main elements produced are rounded surfaces with striation and numerous etching pits in the form of triangles [62]. In the case of impact diamonds, such features are also observed, and it is supposed these diamonds remained at a high P-T for some time after the impact event. The environment was likely a complex heterogeneous system consisting of melt, solid components, and fluid. However, many impact diamonds have a porous surface. Therefore, it can be suggested that the similar appearance of porous surfaces of thermochemically treated diamonds and impact diamonds from the Popigai astrobleme 
could be attributed to the effect of metallic agents in the form of micro- or nano-sized objects.
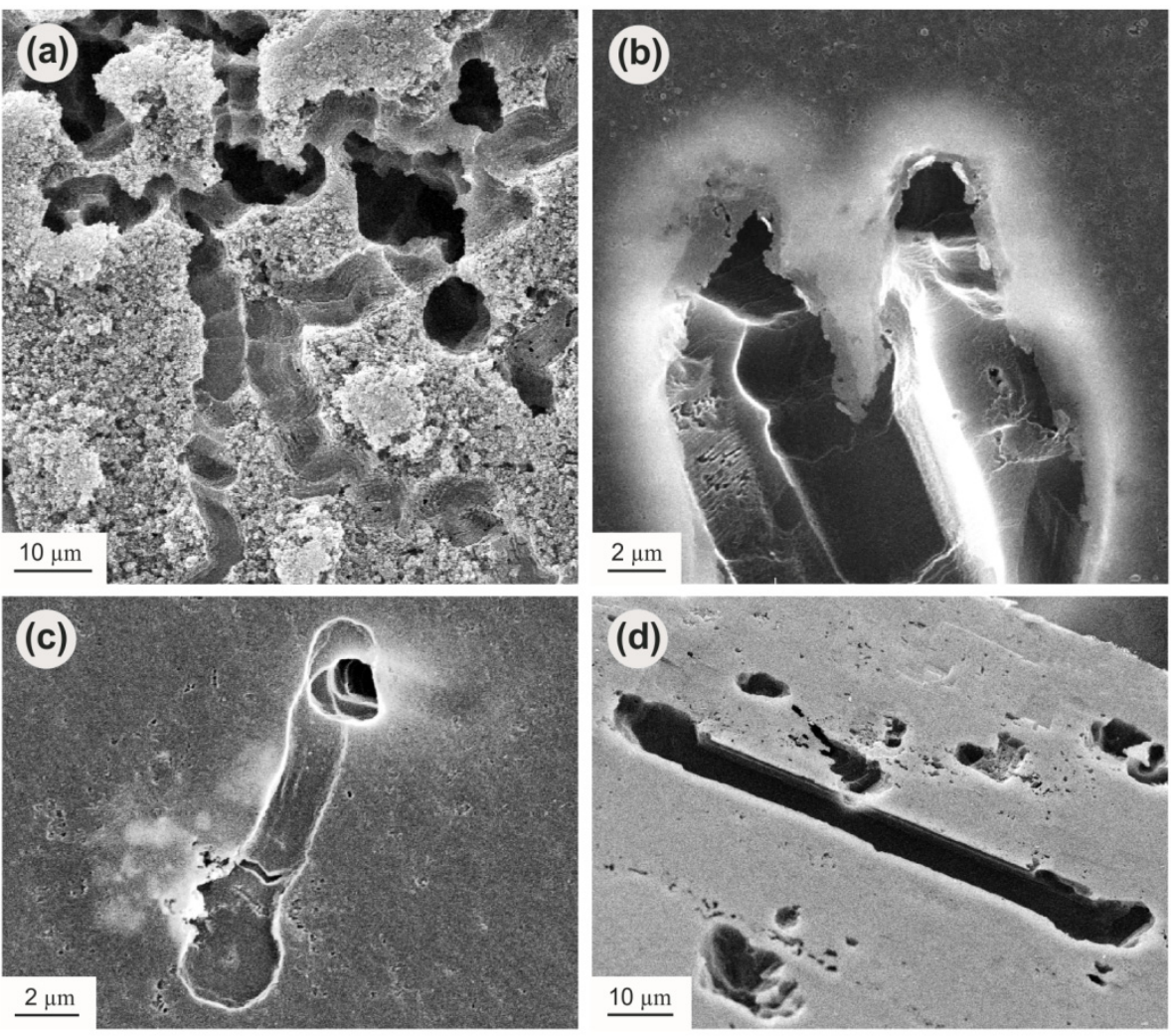

Figure 5. Etching channels produced by migration of iron particles on octahedral (a-c) and cubic (d) diamond surfaces as a result of catalytic hydrogenation.

\section{Conclusions}

A porous surface of diamond was investigated. First, natural crystals were selected and characterized. Second, their surface was etched by catalytic hydrogenation using Fe particles as an etchant. The result was a porous surface throughout the area where the reagent was applied. The etching occurred perpendicular to the crystal surface, with no signs of a tangential etching, and consisted of caverns with a maximal depth of $40 \mu \mathrm{m}$. It is concluded that the porous natural diamond treated by catalytic hydrogenation can be used in composites or as a substrate material. Additionally, the microsculptures obtained were compared with those of natural impact diamond crystals from the Popigai astrobleme. Both diamond types had a strong resemblance in their microrelief elements, indicating a similar mechanism of etching. These findings give new insight into the problem of the post-growth history of impact diamonds, and their industrial uses.

Author Contributions: Conceptualization, writing-original draft preparation, A.C. (Aleksei Chepurov), V.S.; Resources, A.C. (Anatoly Chepurov); Methodology, E.Z.; Investigation, visualization, A.C. (Aleksei Chepurov), D.S., S.S., A.Y. All authors discussed the results and wrote the manuscript. All authors have read and agreed to the published version of the manuscript.

Funding: This research was funded by the Ministry of Science and Higher Education of the Russian Federation grant No. 075-15-2020-781.

Institutional Review Board Statement: Not applicable.

Informed Consent Statement: Not applicable.

Data Availability Statement: Not applicable. 
Acknowledgments: The authors thank two anonymous reviewers for the comprehensive reviewing of the manuscript.

Conflicts of Interest: There is no conflict to declare.

\section{References}

1. Arima, M.; Inoue, M. High pressure experimental study on growth and resorption of diamond in kimberlite melt. In Proceedings of the 6th International Kimberlite Conference, UIGGM SB RAS, Novosibirsk, Russia, 6-12 August 1995; pp. 8-10.

2. Sonin, V.M.; Zhimulev, E.I.; Tomilenko, A.A.; Chepurov, S.A.; Chepurov, A.I. Chromatographic study of diamond etching in kimberlitic melts in the context of diamond natural stability. Geol. Ore Deposit. 2004, 46, 182-190.

3. Kozai, Y.; Arima, M. Experimental study on diamond dissolution in kimberlitic and lamproitic melts at $1300-1420{ }^{\circ} \mathrm{C}$ and $1 \mathrm{GPa}$ with controlled oxygen partial pressure. Am. Mineral. 2005, 90, 1759-1766. [CrossRef]

4. Khokhryakov, A.F.; Pal'yanov, Y.N. The evolution of diamond morphology in the process of dissolution: Experimental data. Am. Mineral. 2007, 92, 909-917. [CrossRef]

5. Arima, M.; Kozai, Y. Diamond dissolution rates in kimberlitic melts at $1300-1500{ }^{\circ} \mathrm{C}$ in the graphite stability field. Eur. J. Mineral. 2008, 20, 357-364. [CrossRef]

6. Sonin, V.M.; Zhimulev, E.I.; Pomazanskiy, B.S.; Zemnuhov, A.L.; Chepurov, A.A.; Afanasiev, V.P.; Chepurov, A.I. Morphological features of diamond crystals dissolved in $\mathrm{Fe}_{0 \cdot 7} \mathrm{~S}_{0 \cdot 3}$ melt at $4 \mathrm{GPa}$ and $1400{ }^{\circ} \mathrm{C}$. Geol. Ore Deposit. 2018, 60, 82-92. [CrossRef]

7. Chepurov, A.I.; Sonin, V.M.; Zhimulev, E.I.; Chepurov, A.A.; Pomazansky, B.S.; Zemnukhov, A.L. Dissolution of diamond crystals in a heterogeneous (metal-sulfide-silicate) medium at $4 \mathrm{GPa}$ and $1400{ }^{\circ} \mathrm{C}$. J. Miner. Petrol. Sci. 2018, 113, 59-67. [CrossRef]

8. Chepurov, A.I.; Sonin, V.M.; Zhimulev, E.I.; Chepurov, A.A. Preservation conditions of CLIPPIR diamonds in the earth's mantle in a heterogeneous metal-sulphide-silicate medium (experimental modeling). J. Miner. Petrol. Sci. 2020, 115, 236-246. [CrossRef]

9. Hyde, M.E.; Jacobs, R.; Compton, R.G. In Situ AFM Studies of Metal Deposition. J. Phys. Chem. B 2002, 106, 11075-11080. [CrossRef]

10. Fujishima, A.; Einaga, Y.; Rao, T.N.; Tryk, D.A. Diamond Electrochemistry; Elsevier Amsterdam-BKC: Tokyo, Japan, $2005 ;$ p. 586.

11. Salazar-Banda, G.R.; Suffredini, H.B.; Avaca, L.A. Improved Stability of PtOx Sol-Gel-Modified Diamond Electrodes Covered with a Nafion ${ }^{\circledR}$ Film. J. Bras. Chem. Soc. 2005, 16, 903-906. [CrossRef]

12. Welch, C.M.; Hyde, M.E.; Banks, C.E.; Compton, R.G. The Detection of Nitrate Using in-situ Copper Nanoparticle Deposition at a Boron Doped Diamond Electrode. Anal. Sci. 2005, 21, 1421-1430. [CrossRef]

13. Simm, A.O.; Ji, X.; Banks, C.E.; Hyde, M.E.; Compton, R.G. AFM studies of metal deposition: Instantaneous nucleation and the growth of cobalt nanoparticles on boron-doped diamond electrodes. Chemphyschem 2006, 7, 704-709. [CrossRef]

14. Kidalov, S.V.; Shakhov, F.M. Thermal Conductivity of Diamond Composites. Materials 2009, 2, 2467-2495. [CrossRef]

15. Weber, L.; Tavangar, R. Diamond-based Metal Matrix Composites for Thermal Management made by Liquid Metal InfiltrationPotential and Limits. Adv. Mat. Res. 2009, 59, 111-115. [CrossRef]

16. Piguillem Palacios, S.V.; Hoffmann, N.; Regiart, M.; Rubilar, O.; Tortella, G.; Raba, J.; Fernández-Baldo, M.A. Nanostructured Platforms Integrated to Biosensors: Recent Applications in Agriculture; Biosensors in Agriculture: Recent Trends and Future Perspectives. Concepts and Strategies in Plant Sciences; Pudake, R.N., Jain, U., Kole, C., Eds.; Springer: Cham, Switzerland, 2021.

17. Artini, C.; Muolo, M.L.; Passerone, A. Diamond-metal interfaces in cutting tools: A review. J. Mater. Sci. 2012, 47, 3252-3264. [CrossRef]

18. Field, E.J. The Properties of Natural and Synthetic Diamond; Academic Press: London, UK, 1992.

19. Masuda, H.; Watanabe, M.; Yasui, K.; Tryk, D.A.; Rao, T.N.; Fujishima, A. Fabrication of a nanostructured diamond honeycomb film. Adv. Mater. 2000, 12, 444-447. [CrossRef]

20. Honda, K.; Rao, T.N.; Tryk, D.A.; Fujishima, A.; Watanabe, M.; Yasui, K.; Masuda, H. Fabrication of through-hole diamond membranes by plasma etching using anodic porous alumina mask. Electrochem. Solid St. 2001, 4, 101-103. [CrossRef]

21. Li, C.Y.; Hatta, A. Electronic and structural properties on nanowhiskers fabricated on iron coated diamond films by radio frequency $\mathrm{O}_{2}$ plasma etching. J. New Mat. Electr. Sys. 2007, 10, 221-224.

22. Kuroshima, H.; Makino, T.; Yamasaki, S.; Matsumoto, T.; Inokuma, T.; Tokuda, N. Mechanism of anisotropic etching on diamond (111) surfaces by a hydrogen plasma treatment. Appl. Surf. Sci. 2017, 422, 452-455. [CrossRef]

23. Ralchenko, V.G.; Kononenko, T.V.; Pimenov, S.M.; Chernenko, N.V.; Loubnin, E.N.; Armeyev, V.Y.; Zlobin, A.Y. Catalytic interaction of $\mathrm{Fe}, \mathrm{Ni}$ and Pt with diamond films: Patterning applications. Diam. Relat. Mater. 1993, 2, 904-909. [CrossRef]

24. Sonin, V.M.; Chepurov, A.I.; Fedorov, I.I. The action of iron particles at catalyzed hydrogenation of $\{100\}$ and $\{110\}$ faces of synthetic diamond. Diam. Relat. Mater. 2003, 12, 1559-1562. [CrossRef]

25. Ohashi, T.; Sugimoto, W.; Takasu, Y. Catalytic etching of $\{100\}$-oriented diamond coating with Fe, Co, Ni, and Pt nanoparticles under hydrogen. Diam. Relat. Mater. 2011, 20, 1165-1170. [CrossRef]

26. Chepurov, A.; Sonin, V.; Shcheglov, D.; Latyshev, A.; Filatov, E.; Yelisseyev, A. A highly porous surface of synthetic monocrystalline diamond: Effect of etching by Fe nanoparticles in hydrogen atmosphere. Int. J. Refract. Met. Hard Mater. 2018, 76, 12-15. [CrossRef]

27. Cui, N.; Wang, F.; Guo, L. Catalytic etching of $\{100\}$-oriented diamond coating with Ni and Cu nanoparticles under hydrogen. Int. J. Mod. Phys. B 2020, 34, 2050062. [CrossRef]

28. Cui, N.; Wang, F.; Ding, H.; Guo, L. Investigation of $<100>$-oriented etching pattern on diamond coated with Ni and Cu. Int. J. Mod. Phys. B 2020, 34, 2050155. [CrossRef] 
29. Wang, J.; Su, Y.; Tian, Y.; Xiang, X.; Zhang, J.; Li, S.; He, H. Porous single-crystal diamond. Carbon 2021, 183, 259-266. [CrossRef]

30. Chepurov, A.A.; Sonin, V.M.; Dereppe, J.M.; Zhimulev, E.I.; Chepurov, A.I. How do diamonds grow in metal melt together with silicate minerals? An experimental study of diamond morphology. Eur. J. Mineral. 2020, 32, 41-55. [CrossRef]

31. Fedorov, I.I.; Chepurov, A.I.; Sonin, V.M.; Chepurov, A.A.; Logvinova, A.M. Experimental and thermodynamic study of the crystallization of diamond and silicates in a metal-silicate-carbon system. Geochem. Int. 2008, 46, 340-350. [CrossRef]

32. Masaitis, V.L. Diamond-Bearing Impactites of the Popigai Astrableme; VSEGEI: St. Petersburg, Russia, 1998. (In Russian)

33. Yelisseyev, A.P.; Afanasiev, V.P.; Panchenko, A.V.; Gromilov, S.A.; Kaichev, V.V.; Saraev, A.A. Yakutites: Are they impact diamonds from the Popigai crater? Lithos 2016, 265, 278-291. [CrossRef]

34. Kryukov, V.A.; Tolstov, A.V.; Afanasiev, V.P.; Samsonov, N.Y.; Kryukov, Y.V. Ensuring the Russian High-Tech Industry Resources by Products Based on Giant Fields of The Arctic-Tomtor Niobium-Rare-Earth and Ultra-Hard Abrasive Popigai Material; Interexpo GEO-Siberia 3; SSUGT: Novosibirsk, Russia, 2016; pp. 188-192. (In Russian)

35. Yelisseyev, A.; Khrenov, A.; Afanasiev, V.; Pustovarov, V.; Gromilov, S.; Panchenko, A.; Pokhilenko, N.; Litasov, K. Luminescence of natural carbon nanomaterial: Impact diamonds from the Popigai astrobleme. Diam. Relat. Mater. 2015, 58, 69-77. [CrossRef]

36. Afanasiev, V.; Gromilov, S.; Sonin, V.; Zhimulev, E.; Chepurov, A. Graphite in rocks of the Popigai impact crater: Residual or retrograde? Turk. J. Earth Sci. 2019, 28, 470-477. [CrossRef]

37. Zaitsev, A.M. Optical Properties of Diamond: A Data Handbook; Springer: Berlin/Heidelberg, Germany, 2001. [CrossRef]

38. Woods, G.S.; van Wyk, J.A.; Collins, A.T. The Nitrogen Content of Type Ib Synthetic Diamond. Phil. Mag. 1990, B62, 589-595. [CrossRef]

39. Boyd, S.R.; Kiflawi, I.; Woods, G.S. IR Absorption by the B Nitrogen Aggregate in Diamond. Phil. Mag. 1995, B72, 351-361. [CrossRef]

40. Chepurov, A.I.; Sonin, V.M.; Dereppe, J.-M. The channeling action of iron particles in the catalyzed hydrogenation of synthetic diamond. Diam. Relat. Mater. 2000, 9, 1435-1438. [CrossRef]

41. Chepurov, A.I.; Sonin, V.M.; Shamaev, P.P. Using catalytic hydrogenolysis for brazing diamond tools. Weld. Int. 2002, 16, 978-980. [CrossRef]

42. Chepurov, A.I.; Sonin, V.M.; Shamaev, P.P.; Yelisseyev, A.P.; Fedorov, I.I. The action of iron particles at catalyzed hydrogenation of natural diamond. Diam. Relat. Mater. 2002, 11, 1592-1596. [CrossRef]

43. Lifshits, S.K.; Grigor'ev, A.P.; Shamaev, P.P. Effect of Different Metals on Catalyzed Hydrogenation of Carbon (Diamond). Izv. Sib. Otd. Akad. Nauk SSSR Ser. Khim. Nauk 1990, 5, 135-139. (In Russian)

44. Sonin, V.M.; Chepurov, A.I. The Interaction of Diamond and Disperse Metals of the Iron Group in a Hydrogen Atmosphere. Inorg. Mater. 1994, 30, 411-414.

45. Sonin, V.M.; Chepurov, A.I. Diamond Hydrogenation in the Presence of Iron Powder. Inorg. Mater. 1996, 32, $373-375$.

46. Sonin, V.M. Interaction of fine Fe particles with structural defects on $\{111\}$ faces of synthetic diamond crystals in a hydrogen atmosphere. Inorg. Mater. 2004, 40, 20-22. [CrossRef]

47. Chepurov, A.I.; Sonin, V.M.; Chepurov, A.A.; Zhimulev, E.I.; Tolochko, B.P.; Eliseev, V.S. Interaction of diamond with ultrafine Fe powders prepared by different procedures. Inorg. Mater. 2011, 47, 864-868. [CrossRef]

48. Bogatyreva, G.P.; Kruk, V.B.; Sokhina, L.A. Determination of diamond content in the diamond-bearing materials. Sintet. Almazy 1974, 5, 19-21.

49. Orlov, Y.L. The Mineralogy of Diamond; JohnWiley: New York, NY, USA, 1977; p. 233.

50. Collins, A.T.; Kanda, H.; Kitawaki, H. Colour changes produced in natural brown diamonds by high-pressure, high-temperature treatment. Diam. Relat. Mater. 2000, 9, 113-122. [CrossRef]

51. Collins, A.T. The detection of colour-enhanced and synthetic gem diamonds by optical spectroscopy. Diam. Relat. Mater. 2003, 12, 1976-1983. [CrossRef]

52. Dobrinets, I.A.; Vins, V.G.; Zaitsev, A.M. HPHT-Treated Diamonds: Diamonds Forever; Springer: Heidelberg, Germany, 2013. [CrossRef]

53. Shigley, J.E.; Breeding, C.M. Optical defects in diamond: A quick reference chart. Gems. Gemol. 2013, 45, 107-111. [CrossRef]

54. Gurney, J.J.; Helmstaedt, H.H.; Richardson, S.H.; Shirey, S.B. Diamonds through Time. Econ. Geol. 2010, 105, 689-712. [CrossRef]

55. Yelisseyev, A.; Meng, G.S.; Afanasiev, V.; Pokhilenko, N.; Pustovarov, V.; Isakova, A.; Lin, Z.S.; Lin, H.Q. Optical properties of impact diamonds from the Popigai astrobleme. Diam. Relat. Mater. 2013, 37, 8-16. [CrossRef]

56. Kadik, A.A.; Lukanin, O.A. Outgassing of the Upper Mantle Upon Melting; Nauka: Moscow, Russia, 1986; p. 97. (In Russian)

57. Vishnevsky, S.A.; Raitala, J.; Gibsher, N.A.; Okhman, T.; Palchik, N.A. Impact tuffisites of the Popigai astrobleme. Rus. Geol. Geophys. 2006, 47, 711-730.

58. Vishnevsky, S.A.; Ivashchenko, V.I.; Raitala, J.; Palchik, N.A.; Leonova, I.V. Impact metamorphic carbon material and the host impactites from the Janisjärvi impact crater, Karelia; new data. Geologiyai Poleznye Iskopaemye Karelii 2004, 7, 185-192. (In Russian)

59. Schmitt, R.T.; Lapke, C.; Lingemann, C.M.; Siebenschock, M.; Stöffler, D. Distribution and origin of impact diamonds in the Ries crater, Germany. Geol. Soc. Am. Spec. Pap. 2005, 384, 299-314. [CrossRef]

60. Pratesi, G. Impact diamonds: Formation, mineralogical features and cathodoluminescence properties. In Cathodoluminescence and Its Application in the Planetary Sciences; Gucsik, A., Ed.; Springer: Berlin/Heidelberg, Germany, 2009.

61. Osovetsky, B.M.; Naumova, O.B. The micro- and nanoforms of impact diamonds surface. Bull. Perm Univ. Geol. 2014, 2, 8-19. (In Russian) [CrossRef]

62. Orlov, Y.L. Diamond Morphology; Izd. AN SSSR: Moscow, Russia, 1963. (In Russian) 